\title{
COMPARISON OF ACTUAL GROUND SETTLEMENTS IN TUNNELLING EXCAVATION TO MODEL PREDICTIONS
}

\author{
Alexandra Saplachidi $^{a, *}$, Emmanouil Vougioukas $^{b}$ \\ ${ }^{a}$ National Technical University of Athens (Ntua), 9 Georgiou Pop, Neo Psychiko, Athens, Greece \\ ${ }^{b}$ National Technical University of Athens (Ntua), 5 Iroon Polytechniou, Zografou, Athens, Greece \\ * corresponding author: sapalex1990@gmail.com
}

\begin{abstract}
It has been discovered that the underground structures are vulnerable to seismic phenomena mainly due to permanent ground deformations caused by earthquakes rather than the dynamic seismic movement itself. Several models (empirical formulae) have been developed to estimate such deformations. In this paper, measured settlements from the tunnelling excavation for the extension of Line 3 of the Athens Metro (from Egaleo station to Chaidari) are used for the verification and calibration of such formulae.

Firstly, some general information is presented concerning the progress of Line 3 so far. Typical buildings, infrastructure and utility grids that can affect the design and construction of the tunnel are examined. Typical geological, hydrogeological and geotechnical conditions along the axis of the excavation, as specified by laboratory tests, are presented as well. According to these conditions, ground settlements are predicted along the tunnel.

Secondly, a comparison is made of the actual values of the ground settlements, which come from geotechnical and structured observations, and the estimates provided by the empirical formulae. Some improvements are proposed for this formulae through the RS2 software program (Phase 2 v.9.0) by Rocsience. The improved model is then used to estimate strains that could be induced by future earthquakes.
\end{abstract}

KEYWORDS: lifelines; tunnel excavations; ground settlements; data monitoring; finite element method.

\section{INTRODUCTION}

The geotechnical and geomechanical characteristics of the soil as well as the existence of groundwater in the subsoil can affect the tunnelling excavation. One of the major case studies concerning excessive ground surface settlements during tunnelling is the extension of Line 3 of the Metro tunnel construction in Athens.

The construction of Line 3 commenced in November 1992. The first seven stations of the Line in the Syntagma-Ethniki Amyna section were opened to the public in January 2000, while the last section of the Base Project, Syntagma-Monastiraki section comprising $1.4 \mathrm{~km}$ of tunnels and one station, was commissioned in April 2003.

The extension from Egaleo to Chaidari is the first section of the extension of Line 3 of the Athens Metro (Figure 1). It includes the tunnelling of the double and triple line of the length of $1.31 \mathrm{~km}$ using conventional mechanical means. The method of excavation used was the NATM.

The NATM first came to prominence in the $1960 \mathrm{~s}$, and helped to revolutionize the tunnelling industry. The main principle behind NATM that differs from other tunnelling methods is that it uses the inherent geological strength available in the surrounding rock mass to stabilize the tunnel, therefore, lowering the costs. The optimal method of support is determined based on actual observed ground conditions. The initial ground support is provided by shotcrete in a combination with fibre or welded-wire fabric reinforcement, lattice girders and ground reinforcement.

Through this Metro extension to one more area of the Western Suburbs of the Attica region, ATTIKO METRO S.A. provides the optimum possible transportation services to the involved Municipalities, offers fast and safe transportation, and actually upgrades these areas.

\section{Description of the PROJECT}

In this study, a tunnel section from the Alsos Well $(\mathrm{CH} 0+000)$ to the Iroon Politechniou Well $(\mathrm{CH} 0+500)$ was considered. For the selection of the route, the buildings, infrastructures and social utility networks were included in order to reduce all possible risks for the project. Along the engraving, up to the point $\mathrm{CH} 0+200$, the tunnel passes under a one (1) one storey building, two (2) two storey buildings, two (2) three storey buildings and a gas station.

In the rest of the section, it passes underneath the Iera Odos Avenue. As it can be seen from the utility grids, four (4) wells and a putrefactive cesspool were detected (Figure 2). 


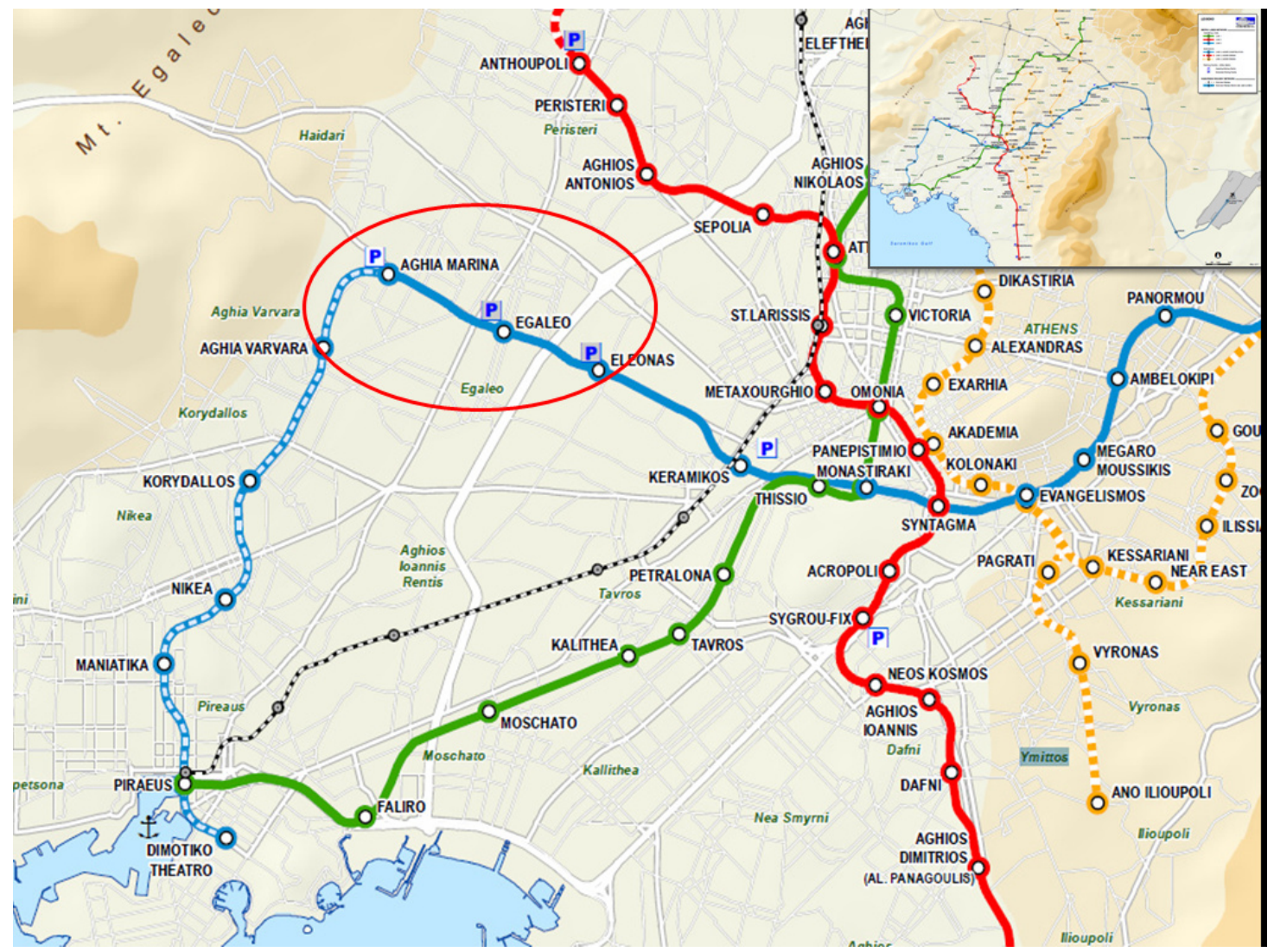

Figure 1. Western extension Egaleo-Chaidari of Line 3 of the Athens Metro. The area of interest marked by the red line.

\section{The GeOlOGiCAL AND \\ GEOTECHNICAL CONDITIONS OF THE PROJECT}

The geological bedrock mainly consists of the Athenian Schists formation. The Athenian Schist series extending at the two edges of the extension of the Athens Metro. This formation is intensively heterogeneous and metamorphic and contains granites and metasiltstones on the upper horizon and graywatches and shale schists on the lower one.

Up to this formation, postalpine sediments of the Neogene have been deposited, which include mostly marl and madstones on the upper horizon and carbon siltstones, sandstones and conglomerates on the lower one. Quaternary deposits, lacustrine-lacustrine terrestrial, have been deposited on the Neogene deposits or on the Athenian Schists in positions without posts of great erosion of the Neogene cover [9].

The evaluation of the results of the geotechnical research, is conducted during the phase of the final study as well as the application study, which included thirty-eight (38) drillings and numerous on-spot laboratory tests. The geological-geotechnical grade line prediction of the project was drafted, as illustrated in Figure 3 including the basic geotechnical sections in the project area. According to the grade line along the engraving of the tunnel, the following formations are met.
- Section A: From $\mathrm{CH} 0+000$ to $\mathrm{CH} 0+120$. In this section, the hosted formation is the Athenian Schists of the upper and lower horizons. The ground surface ranges from $+43 \mathrm{~m}$ to $+43.5 \mathrm{~m}$, whereas the absolute altitude of the centre line ranges from $+14.7 \mathrm{~m}$ to $+16.5 \mathrm{~m}$, and the upper level of the aquifer ranges from $+37 \mathrm{~m}$ to $+39.4 \mathrm{~m}$.

- Section B: From CH0+120 to CH0+180. The transition between the Athenian Schists (upper horizon) and the Neogene formation is visible. The ground surface ranges from $+42.5 \mathrm{~m}$ to $+43 \mathrm{~m}$, whereas the absolute altitude of the center line goes from $+16.5 \mathrm{~m}$ to $+18.7 \mathrm{~m}$. The upper level of the aquifer ranges from $+38 \mathrm{~m}$ to $+38.7 \mathrm{~m}$.

- Section C: From CH0+180 to $\mathrm{CH} 0+500$. In the last part of the study area, the hosted formation is the upper horizons of the Neogene deposits. The ground surface ranges from $+42.5 \mathrm{~m}$ to $+56.5 \mathrm{~m}$, whereas the absolute altitude of the centre line goes from $+18.5 \mathrm{~m}$ to $+38.8 \mathrm{~m}$. The upper level of the aquifer ranges from $+39.7 \mathrm{~m}$ to $+50 \mathrm{~m}$.

\section{Geotechnichl planning}

Initially, through the classification of the formations, which was done by the laboratory tests the geotechnical design parameters were defined. The results of the tests show that the formation were distinguished into the following categories: grand surface with low 


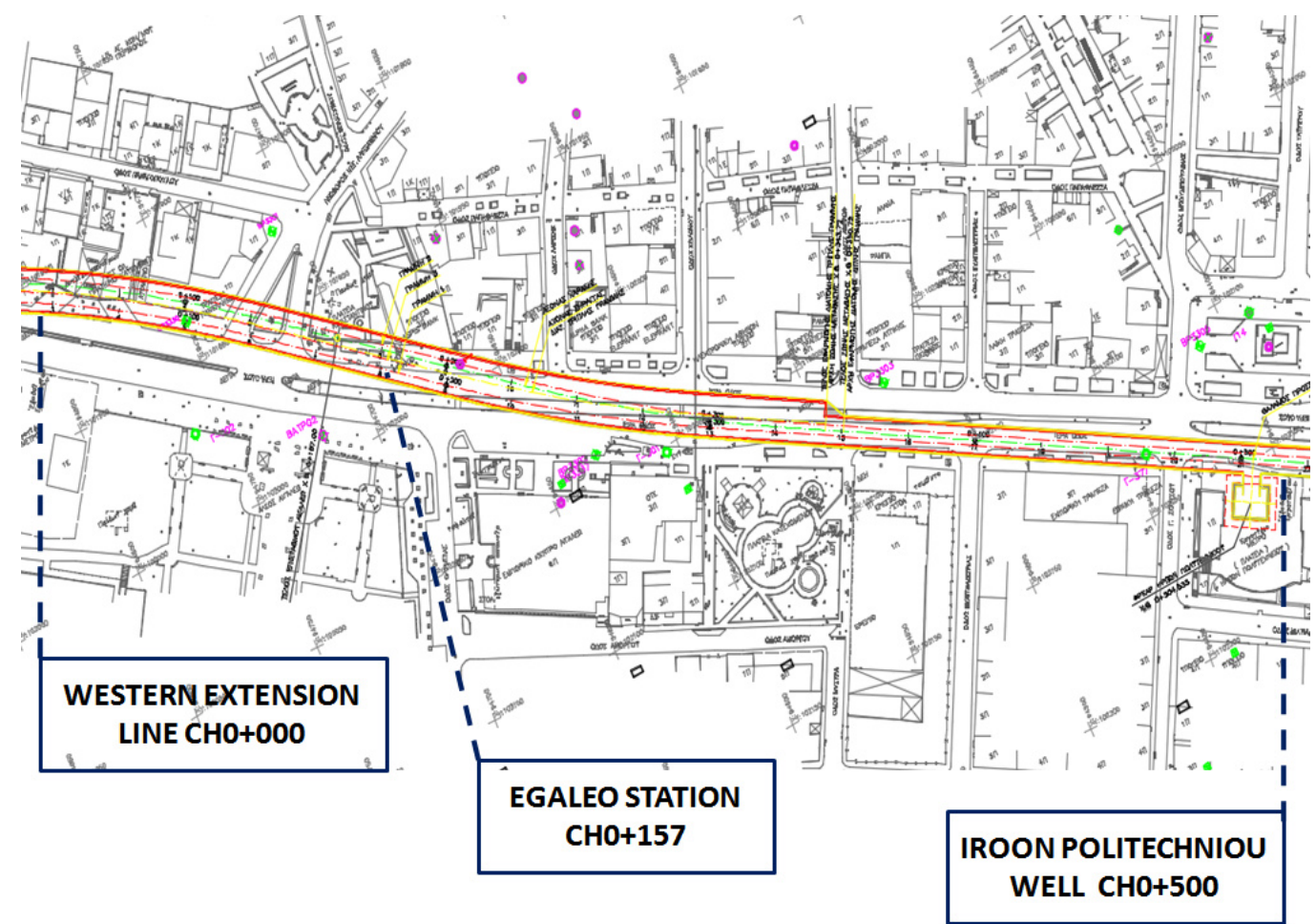

Figure 2. Plan view of the alignment of Egaleo-Chaidari extension of Line 3.

\begin{tabular}{lcccc}
\hline Scope & $\begin{array}{c}\gamma \\
\left(\mathrm{kN} / \mathrm{m}^{3}\right)\end{array}$ & $\begin{array}{c}c^{\prime} \\
(\mathrm{kPa})\end{array}$ & $\begin{array}{c}\varphi^{\prime} \\
\left(^{\circ}\right)\end{array}$ & $\begin{array}{c}E \\
(\mathrm{MPa})\end{array}$ \\
\hline Rock C in the & 21 & 0 & 38 & 40 \\
excavation face & 23 & 70 & 38 & 800 \\
\hline Rock D in the & 21 & 0 & 38 & 40 \\
excavation face & 23 & 50 & 35 & 500 \\
\hline Rock E in the & 21 & 0 & 38 & 40 \\
excavation face & 23 & 40 & 30 & 350 \\
\hline Soft Rock in the & 21 & 0 & 38 & 40 \\
excavation face & 22 & 35 & 28 & 250 \\
\hline
\end{tabular}

TABLE 1. Athenian Schists - Section A, Geotechnical Design Parameters 3 .

geotechnical characteristics, dry ground, and hard ground with better geotechnical characteristics. The geomechanics classification of the rocky formations was based on the Geological Strength Index (GSI) of the rock.

The specification of the geotechnical design parameters was completed by the assessment of the results in-situ and laboratory tests, in order to classificate the rock mass (GSI indicator) and estimate the empirical correlations. Analyses were conducted using active soil parameters in drained conditions. Due to the low permeability of the formations, it can be assumed that the stress-pore pressures remain unchanged in a short distance around the tunnel and equal to the initial hydrostatic pressure. The stress-pore pressures are

\begin{tabular}{lcccc}
\hline Scope & $\begin{array}{c}\gamma \\
\left(\mathrm{kN} / \mathrm{m}^{3}\right)\end{array}$ & $\begin{array}{c}c^{\prime} \\
(\mathrm{kPa})\end{array}$ & $\begin{array}{c}\varphi^{\prime} \\
\left({ }^{\circ}\right)\end{array}$ & $\begin{array}{c}E \\
(\mathrm{MPa})\end{array}$ \\
\hline Rock C in the & 21 & 0 & 38 & 40 \\
excavation face & 23 & 60 & 36 & 1200 \\
\hline Rock D in the & 21 & 0 & 38 & 40 \\
excavation face & 23 & 50 & 35 & 750 \\
\hline Rock E in the & 21 & 0 & 38 & 40 \\
excavation face & 23 & 45 & 32 & 450 \\
\hline Soft Rock in the & 21 & 0 & 38 & 40 \\
excavation face & 23 & 35 & 32 & 300 \\
\hline
\end{tabular}

TABle 2. Neogene - Section B, Geotechnical Design Parameters 4.

zero in the walls because of the drainage holes.

The rate of the strength parameters and deformability of the formations used for the numerical analyses of the tunnelling excavation method. The Geotechnical Design Parameters are presented in the following Tables 1 and 2 for the Athenian Schists and Neogene correspondingly.

\section{TheORETICAL PREDICTIONS OF SETTLEMENTS}

Specifying the intensive sizes of the temporary investment and predicting the convergence of the tunnel and the surface settlements was done by numerical analyses of the opening of the tunnel that were per- 


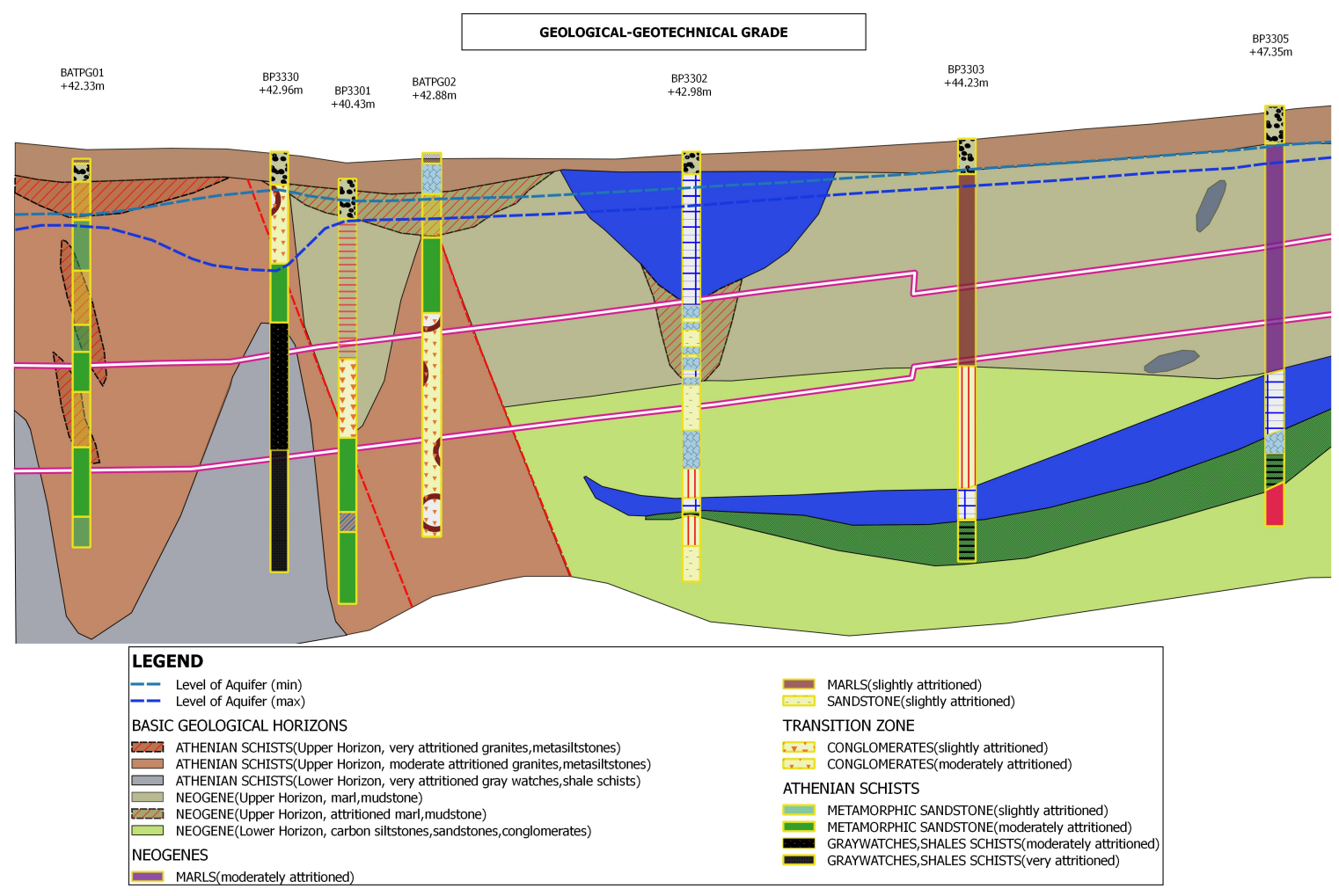

FIGURE 3. Foreseen geological-geotechnical cross-section of the project [3].

\begin{tabular}{lccc}
\hline & $\begin{array}{c}\text { Sensitive building } \\
\text { or construction }\end{array}$ & $\begin{array}{c}\text { Other types } \\
\text { of buildings }\end{array}$ & $\begin{array}{c}\text { Streets, pavements } \\
\text { or utility networks }\end{array}$ \\
\hline Total settlement & $20 \mathrm{~mm}$ & $25 \mathrm{~mm}$ & $30 \mathrm{~mm}$ \\
Angle deformation & $1 / 800$ & $1 / 600$ & $1 / 600$ \\
Horizontal deformation & $0.15 \%$ & $0.25 \%$ & $0.30 \%$ \\
\hline
\end{tabular}

TABle 3. Permissible settlement values.

formed for each category of the temporary support with the help of the FLAC simulation model.

The transition from the double to triple bisection had a length of $7 \mathrm{~m}$ from the $\mathrm{CH} 0+343.72$ to the $\mathrm{CH} 0+350.72$. It was suggested that the excavation should be carried out following the support categories SE and SSR.

The three support patterns were designed in order to secure the stability of the front of the tunnel.

They are as follows:

- F1 category that is applied in the field support SD;

- F2 category that is applied in the SE;

- F3 category that is applied in the SSR.

The support categories SC (Support for rock C), SD (Support for rock D), SE (Support for rock E) and SSR (Support for Soft Rock) refer to taking appropriate measures to perform a safe construction by limiting the wall deformations.

The quantitative measure for the support design is the supporting load, which is theoretically exercised by the support measures to the surrounding rock. A tunnel may be invisible or unsupported when the geomechanical conditions allow; it, in this case the support load is zero.

The support measures concern constructions that undertake the supporting load. Depending on the construction methodology they are placed as a final investment or temporary support measures. The most common support measures are:

- shotcrete;

- anchors and nails;

- frames (steely or wooden);

- lattice girders;

- structural grids;

- prefabricated elements (e.g. in a TBM construction).

In the first case, the excavation face of the tunnel is expected to be friable where possible block falls occur if measures of a temporary support are not taken. 


\begin{tabular}{|c|c|c|c|c|c|c|c|c|c|c|}
\hline \multirow[t]{2}{*}{ Design category } & \multicolumn{4}{|c|}{ Subsection A1 } & \multicolumn{3}{|c|}{ Subsection A2 } & \multicolumn{3}{|c|}{ Section B } \\
\hline & $\mathrm{SC}$ & SD & $\mathrm{SE}$ & SSR & $\mathrm{SC}$ & SD & $\mathrm{SE}$ & $\mathrm{SC}$ & SD & $\mathrm{SE}$ \\
\hline Comp & 4.9 & 9.0 & 15.6 & 17.7 & 4.9 & 9.0 & 15.6 & 5.1 & 9.6 & 15.3 \\
\hline Com & 5.3 & 9.5 & 19.7 & 21.8 & 5.3 & 9.5 & 19.7 & 5.7 & 10.4 & 18.5 \\
\hline aquifer $(\mathrm{mm}$ & 1.2 & 1.7 & 2.0 & 2.9 & 1.2 & 1.7 & 2.0 & 1.3 & 2.2 & 3.3 \\
\hline Comp & 6.5 & 11.2 & 21.7 & 24.7 & 6.5 & 11.2 & 21.7 & 7.0 & 12.6 & 21.8 \\
\hline$R=s(\mathrm{~mm})$ & 6.5 & 11.5 & 22.0 & 25.0 & 6.5 & 11.5 & 22.0 & 7.0 & 13.0 & 22.0 \\
\hline Warning Limit $T=0.80 R(\mathrm{~mm})$ & 5.5 & 9.5 & 17.5 & 20.0 & 5.5 & 9.5 & 17.5 & 6.0 & 10.5 & 18.0 \\
\hline Limit Alarm $L=1.20 R(\mathrm{~mm})$ & 8.0 & 14.0 & 26.5 & 30.0 & 8.0 & 14.0 & 26.5 & 8.5 & 16.0 & 26.5 \\
\hline
\end{tabular}

TABLE 4. Maximum settlements on ground surface [2].

In the second and third case, the front of the tunnel isn't expected to be stable a and there is a possibility of an accident, if the stabilization measures are not taken, as the front is cumbered by the presence of discontinuities on the face. Finally, the F2 Category is also applied in cases of an especially unstable front despite the applied support category. In the case of $\mathrm{CH} 0+349$ to $\mathrm{CH} 0+500$, three categories of measures of temporary support were designed:

- GDS-2 (Rock C), treated by the SC Category;

- GDS-3 (Rock D), treated by the SD Category;

- GDS-4 (Rock E) and GDS-5 (overlooking Soft Rock with Rock D on the face), treated by the SE Category.

The values in Table 3 were calculated as permissible values for the total settlement on the surface of the ground, the angle deformation and the horizontal deformation.

The maximum settlement on the ground surface due to the drop of the aquifer for every section and every design category is outlined in Table 4. The value warning is defined up to $80 \%$ of the reference value, whereas the limit alarm is taken as $120 \%$ of the reference value. These limits are defined in $15 \mathrm{~mm}$ for warning limits and $20 \mathrm{~mm}$ for sensitive and other types of buildings, whereas for roads and utility networks the alarm limits are $20 \mathrm{~mm}$ and $30 \mathrm{~mm}$ respectively 1 .

\section{Real values of Settlements}

Based on the theoretical predictions of the potential surface settlements, the water inflows in the tunnel, the behaviour of the face, the unsupported section and the geomechanical classification of the rock mass dependent on the GSI system, from $\mathrm{CH} 0+000$ to $\mathrm{CH} 0+270$ approximately, the category of the temporary support SE was applied.

In $\mathrm{CH} 0+343$, an increase of surface settlements which locally reached the point of $25 \mathrm{~mm}$ was manifested. Resulting in heavier measures of the temporary support being automatically applied (the category of the temporary support SSR). By the forwarding of the excavation face, a further increase in maximum settlements appeared, which was limited in the $50-55 \mathrm{~mm}$

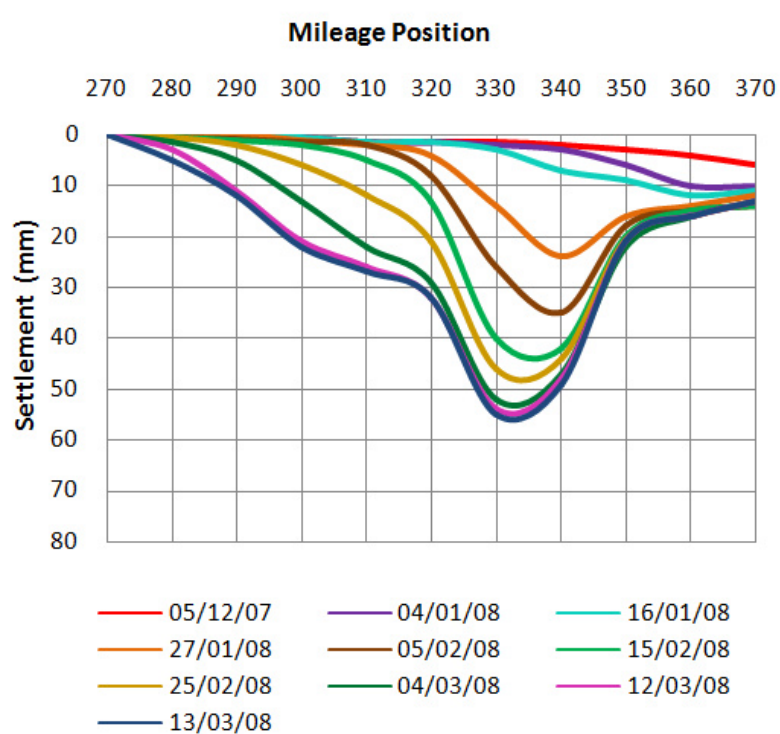

FIGURE 4. Results of the levelling measurements on the ground.

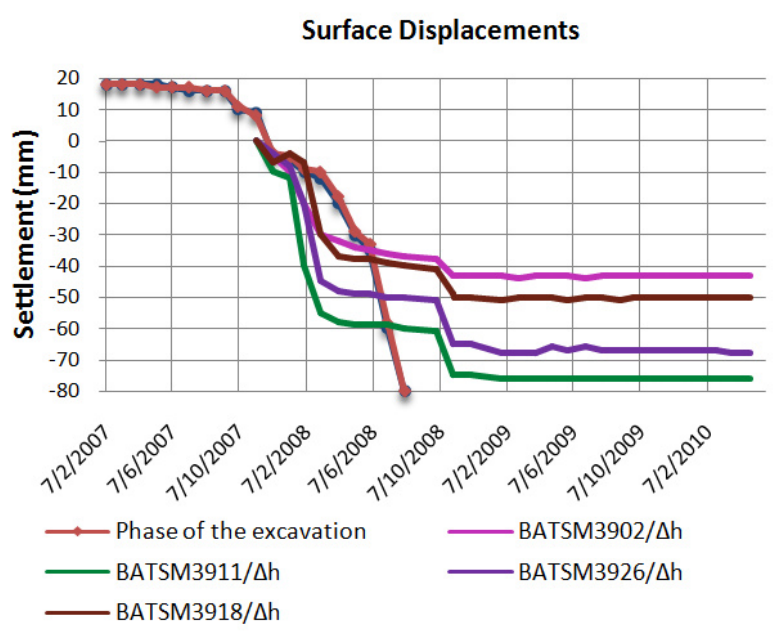

Figure 5. Evolution of the surface settlements in the section of the triple line along the axis with the advancing of the front.

range, with the change of the measures of the temporary support. In this way, the excavation of the triple tunnel was completed without any problems.

Regarding the section of the double line from 


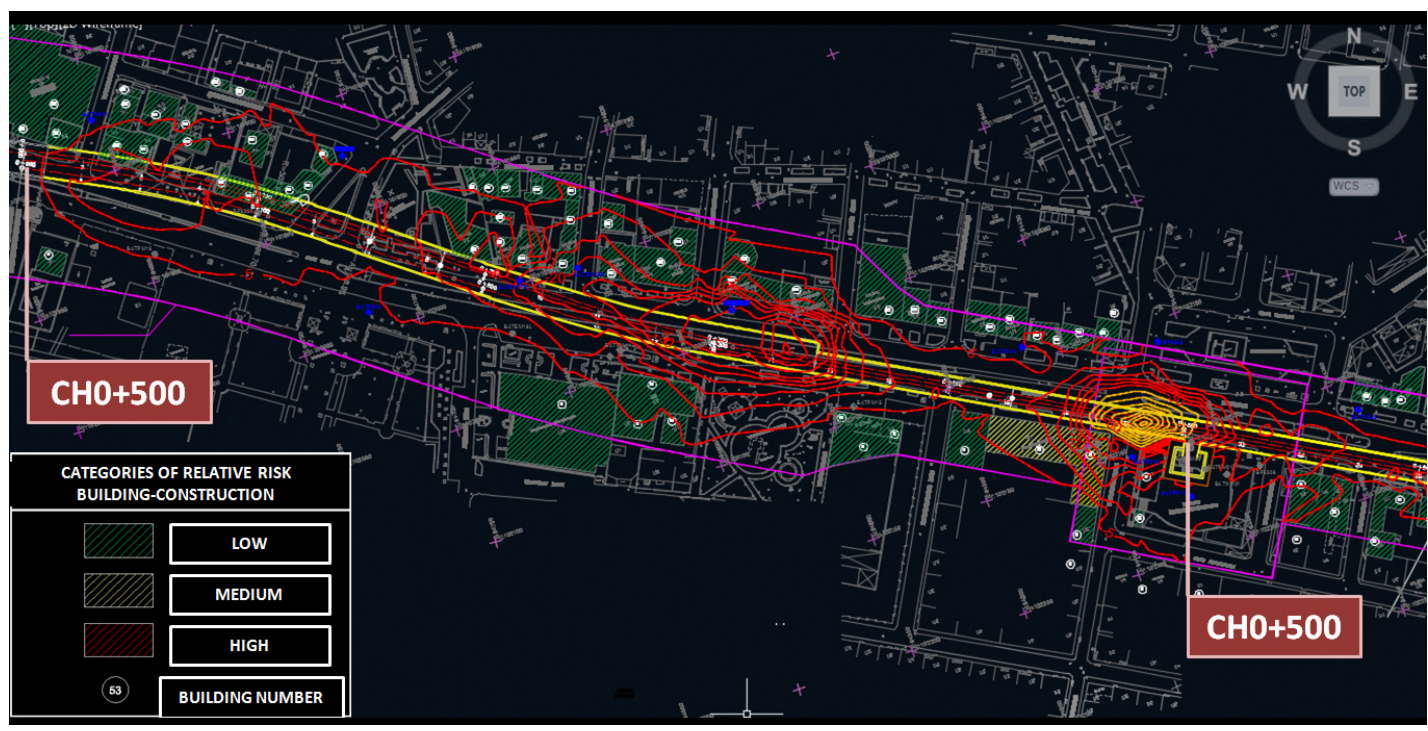

Figure 6. Horizontal graph within $\mathrm{CH} 0+000$ to $\mathrm{CHO}+500$ and imaging of surface settlements.

$\mathrm{CH} 0+349$ to $\mathrm{CH} 0+500$, the excavation was done with measures of the SE support category. During the excavation of the double tunnel in the section from the challenge chamber of the well of the area of Iroon Politechniou from $\mathrm{CH} 0+472.43$ to $\mathrm{CH} 0+500$, surface settlements which exceeded the allowable limits of the study, appeared. Immediately, measures were taken regarding the application of the heavier SSR3 category. Figure 4 presents the total settlements in the section of the triple line which took place during the excavation and Figure 6 presents all settlements in our project: The program of the geomechanical and structural observation of the project indicatively involved the following:

- Levelling spots for measuring the surface settlements of the ground and buildings found in the zone of the project's influence.

- Extensometers and inclinometers for measuring the vertical and horizontal movements in depth.

- Three-dimensional visual targets for measuring movements in the interior of the tunnel and also of the buildings on the ground surface.

- Piezometers for measuring the change of the aquifer.

In our project, the levelling pins were placed on the road surface as well as on the buildings from $\mathrm{CH} 0+270$ to $\mathrm{CH} 0+500$. As far as the levelling pins of the buildings were concerned, the measurements showed maximum surface displacements that reached $32 \mathrm{~mm}$ in relation to the rest of the measurements that ranged within the allowable values suggested during the initial study of the project.

The levelling pins placed on the road surface showed much higher surface settlements, which locally reached up to the $75 \mathrm{~mm}$. These measurements were made within the kilometre posts on which intense sedimentations took place during our project, thereby confirming this abnormality. However, we observed that these events continued after the end of Phase A' of the excavation until they were limited, as better and safer measures of temporary support were taken so the excavation could continue. The following Figure 5 shows the maximum settlements which resulted during the whole range of measurements.

In order to measure the total displacements in three dimensions, reflectors were installed in buildings and constructions within the influence zone of the project.

In our project, the largest vertical displacements $15 \mathrm{~mm}$ appeared on the 152 building in $\mathrm{CH} 0+465$. This value is within the permissible limits of the theoretical pre-assessments for sensitive and non-sensitive buildings (20-25 mm). Whereas for buildings 165 to 168 we had a subsidence up to $18 \mathrm{~mm}$ in $\mathrm{CH} 0+180$ to $\mathrm{CH} 0+200$ as a result of the instability of the face during the excavation [5].

As far as the convergences in the interior of the tunnel are concerned, three-dimensional targets were placed after the positioning of the temporary support measures. The excavation of the tunnel took place in two phases.

There were three targets in the first phase. For every three-dimensional target, the displacement was recorded in the directions $D_{z}, D_{\mathrm{rad}}$ and $D_{\mathrm{CH}}$.

The Dz indicates the vertical displacement with positive values for the upward and negative values for the downward direction.

The drift toward $D_{\text {rad }}$ indicates the horizontal shift in a vertical direction to the axis of the tunnel, with positive measurements to the right and negative to the left. Finally, the displacement toward $D_{\mathrm{CH}}$ indicates the horizontal displacement on the axis of the tunnel, with positive measurements during the mileage measurement and negative during the mileage measurement of the tunnel.

In the section $\mathrm{CH} 0+100$ to $\mathrm{CH} 0+180$, the comparison of the results during the excavation with the theoretical pre-assessments for the convergence in the 
interior of the tunnel confirmed the pre-assessments to a great degree, and the results appeared were within the permissible limit, whereas in the section $\mathrm{CH} 0+180$ to $\mathrm{CH} 0+500$, after the end of the First A' phase of the excavation, higher values of vertical drifts appeared, which exceeded the initial pre-assessments of $19.6 \mathrm{~mm}$. The values of the highest convergences, which fluctuate from -25 to $-38 \mathrm{~mm}$, were located mainly in the section from $\mathrm{CH} 0+337$ to $\mathrm{CH} 0+343$ and up to $-25 \mathrm{~mm}$ in $\mathrm{CH} 0+495$.

\section{COMPARISON OF REAL AND THEORETICAL VALUES}

As we can see in the horizontal graph between $\mathrm{CH} 0+300-360$ and $\mathrm{CH} 0+450-500$ (Figure 6), the real values are higher than the theoretical ones. This happened because the geotechnical parameters of the design that were used in the theoretical studies were done with the sectional estimation of the project, which classified the geological rocks in the larger session of the Neogene. With the increase of the depth, we have two different geological rocks (aluminates and arenacious marls), which, in combination with the intense crevice in the area, are expected to present lower resistance and deformability values, resulting in the real values. Therefore, the goal of this comparison was to check the credibility of the geotechnical survey and the design of the tunnel.

\section{Geotechnical simulation of SOIL SETTLEMENTS}

The aim of the survey is to use geophysical models for a more precise and, as much as possible, a more realistic approach to the mechanism of soil settlements, which relates to the alteration of the level of the underground aquifer and the lithology of the geological formations along the axis of the project. The analyses were made by the RS2 software program (Phase 2 v.9.0) by Rocsience.

The RS2 software program (Phase 2) creates a model of finite elements, which carries out twodimensional analyses for the calculation of stress, deformations and soil hydraulic properties. The team completed the external and excavation boundaries drawing of the digging and the discretization of the boundaries in rudimentary segments. After the design on the cross-section level Oxy, the introduction of the corresponding outline of the hybrid surface by which the digging will be encircled and the study area will be bounded is necessary.

In Phase 2, the intensive field stress is described with the two main stresses in the $O x y$ level - that is, the main axial stress $S_{1}$, the main lateral stress $S_{2}$ and their orientation angle as measured according to the Cartesian level of the $O x y$ coordinates, which is defined as the angle which the strike of $S_{3}$ forms with the positive semi-axis $O x$ as well as by the value of the stress in the $x$-axis. In the model, the geotechnical

\begin{tabular}{lcc}
\hline & $\begin{array}{c}\text { Section A } \\
(\mathrm{CH} 0+343)\end{array}$ & $\begin{array}{c}\text { Section B } \\
(\mathrm{CH} 0+472.43-500)\end{array}$ \\
\hline Width & $B=14.5 \mathrm{~m}$ & $B=9.6 \mathrm{~m}$ \\
Height & $H=16.5 \mathrm{~m}$ & $H=8.0 \mathrm{~m}$ \\
\hline
\end{tabular}

TABLE 5. Excavation dimensions.

parameters of the materials that form the structure of the study area (friction angle $f$, cohesion $c$, Young's Modulus $E$, reason of Poisson $\nu$ ) and the type of the material (elastic or plastic) were defined. In the simulations carried out, the soil and rock layer were assumed to be an elastic material conforming to the Mohr-Coulomb failure criterion together with the nonassociated flow rule proposed by Davis [6].

The sections in $\mathrm{CHO}+343$ and $\mathrm{CH} 0+472,43-500$ in which the highest settlements took place were studied. These sections pass through the formation of the Neogene where the dimensions of the excavation are in Table 5

The height of the overlying grounds for the analysis is $17.4 \mathrm{~m}$ for the triple line tunnel (Section A) and 18.9 for the double line tunnel (Section B). A uniformly distributed load of magnitude $15 \mathrm{kN} / \mathrm{m} 2$, which represents the road traffic load, and a uniformly distributed load of $50 \mathrm{kN} / \mathrm{m} 2$, which represents the most unfavourable load, for five-story buildings that are the maximum encountered in the tunnel transit area, were applied to the surface of the ground.

The nine and six simulation stages that followed were based on the initial study for the design category SE.

After the completion of the simulation model, the results should be controlled and verified if they are suitable for a real life application. There had been a reevaluation of the geological sectors and the drillings of the broader area. It was noted that locally, in the places with high settlements, the Neogene formations consist of clay and arenacious marls, which are intensely cracked.

Section A (CHO+343). This section consists of clay marls. A clay marl is a mixture of clay with carbonates. In the marls, the water circulation is limited, but there is a possibility of the inflow of water of the aquifer because of the intense cracking. Therefore, the formation becomes plastic and presents intense breakage, which causes settlements as a result.

The values that were given to the elastic properties and parameters of the strength of the rocks were not approximate. Real values, which were found in the corresponding project and specifically, in the opening of the tunnel Platanou-Trapezas in the area of Kiato-Aigio [14] were used. The designers followed the following empirical relations, leading them to the relative values that were given to the elastic properties and strength parameters. The relations are the following: 


\begin{tabular}{lccc}
\hline Rock type & Friction angle $\varphi\left(^{\circ}\right)$ & Cohesion $c(\mathrm{kPa})$ & Young's Modulus $E(\mathrm{MPa})$ \\
\hline Clay Marls & $27-32$ & $100-50$ & $100-120$ \\
Arenacious Marls & $25-30$ & $30-40$ & $40-100$ \\
\hline
\end{tabular}

TABLE 6. Geotechnical design parameters for the clay and arenacious marls.

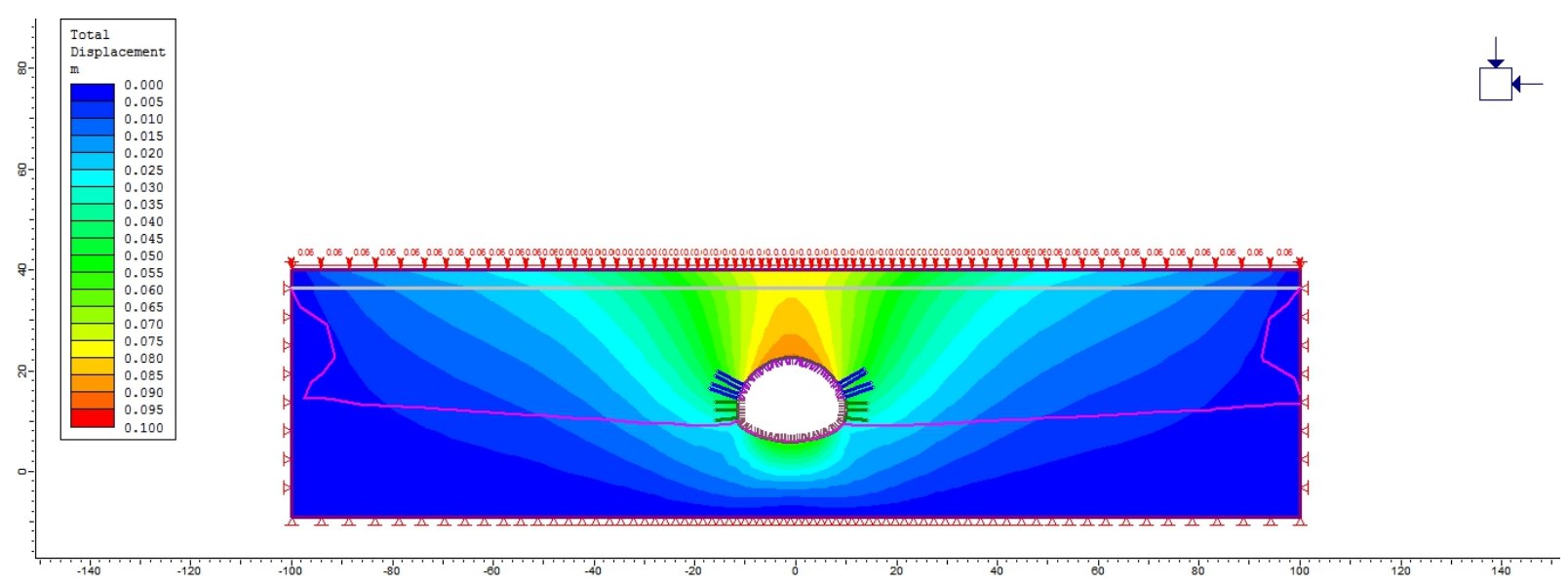

FiguRE 7. Surface settlements for $\mathrm{CH} 0+343$.

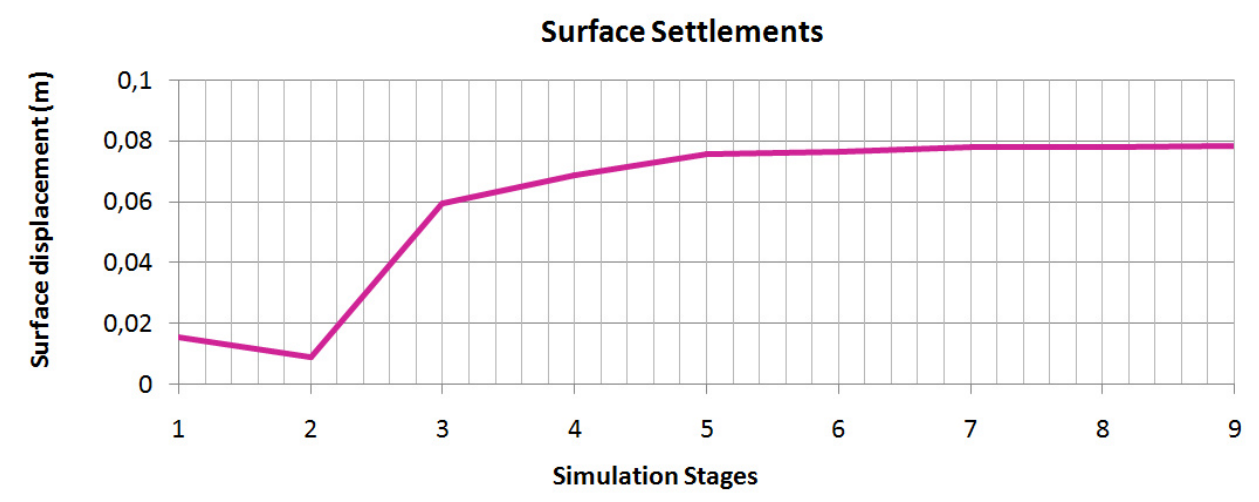

FiguRE 8. Surface settlements for $\mathrm{CH} 0+343$ for every simulation stage.

(1.) According to Stroud-Butler [15]: For $P l=9.8 \%$, $F_{2}=900, E=F_{2} N_{\mathrm{SPT}}$. For $N_{\mathrm{SPT}}=100$, we have $E=90 \mathrm{MPa}$.

(2.) According to Butler [15, for hard clays by tests of standard penetration, then $E_{\mathrm{u}}=N_{\mathrm{SPT}}(1.0 \div 1.2) \approx$ $100 \mathrm{MPa}$, Poisson $\nu=0.3$. From $E_{\mathrm{u}}=\frac{3 E}{2(1+\nu)}$ we have $E=87 \mathrm{MPa}$.

(3.) According to Duncan-Buchignami [7, under drained conditions: For $P l<30 \%, E_{\mathrm{u}}=(600)_{c u}$ and $c u=390 \mathrm{KN} / \mathrm{m}^{2}$, then $E_{\mathrm{u}}=234 \mathrm{MPa}$ with Poisson $\nu=0.3$. From $E_{\mathrm{u}}=\frac{3 E}{2(1+\nu)}$ we have $E=200 \mathrm{MPa}$.

By evaluating the aforementioned ratios and the results of the laboratory tests of the samples, parameters of the geotechnical design were obtained, see Table 6.

By applying these geotechnical design parameters to the Phase 2 software program we obtained the results presented in Figures 7 and 8
Section B (CH0+472-500). This section consists of alternations of clay marl, arenacious marl and in places margaric limestones, which rank in the category of the Neogene formations. A basic characteristic of the arenacious marls is the presence of gaps which are connected directly with the presence of water and must be taken into serious consideration in the foundation of a technical project. It is also noticed that the presence of water usually reduces the mechanical characteristics of the rock, which causes a slackness of rock cohesion.

Therefore, when we are a short distance from the soil surface, surface convergences are possible. The values given to the elastic properties and resistance parameters of the rock were real values, concerning the margaric material with conglomerate inaccuracies (since the conglomerate and arenacious materials have the same mechanical characteristics) found in the corresponding project and specifically in the opening of the tunnel of Platanos-Trapeza in the Kiato-Aigio area [14].

The modulus of elasticity is estimated using the 


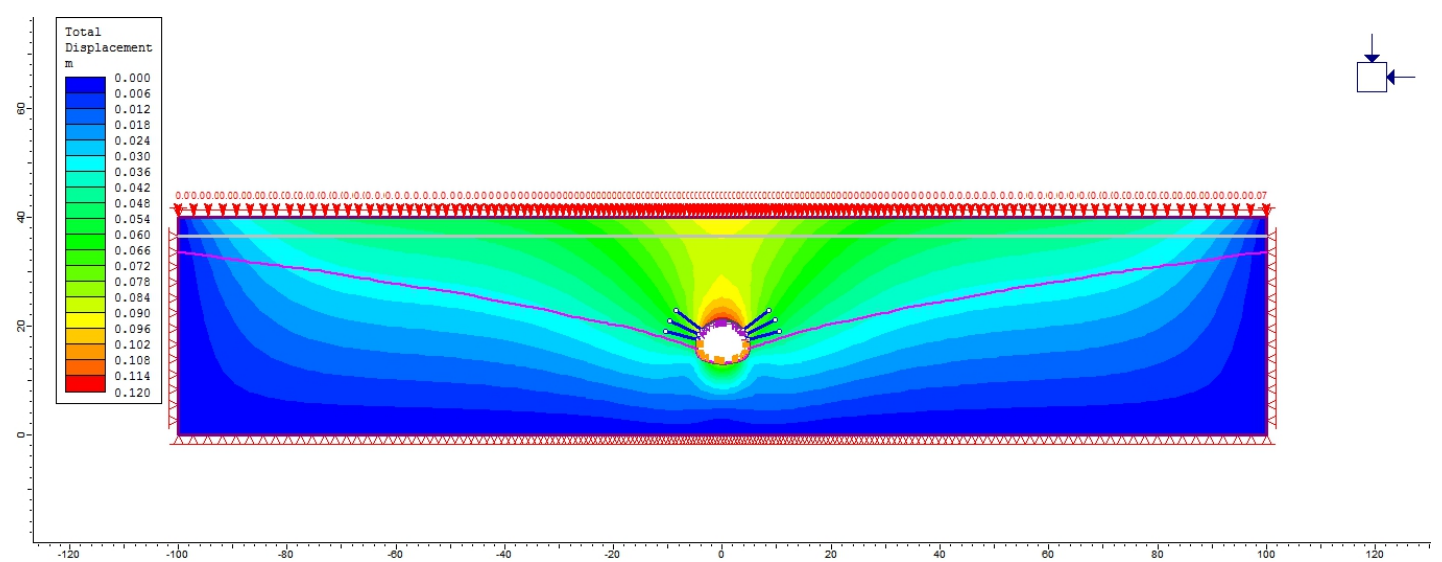

Figure 9. Surface settlements for $\mathrm{CH} 0+472-500$.

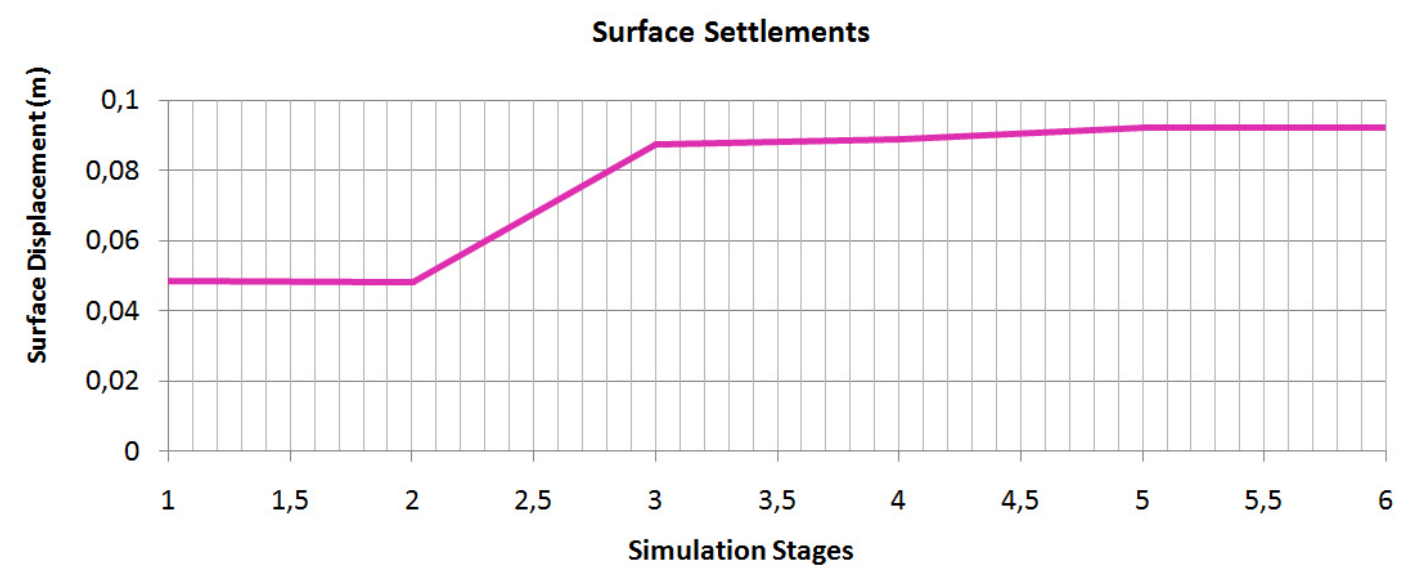

FiguRE 10. Surface settlements for $\mathrm{CH} 0+472-500$ for every simulation stage.

following empirical relations:

For depths over $20 \mathrm{~m}$. According to Schultze and Menzenbach [? ], for sandstone with NSPT $=100$ :

$$
E=C_{1}+C_{2} N_{\mathrm{SPT}}=38+10.5 \cdot 100 \approx 109 \mathrm{MPa} .
$$

According to Tassios and Anagnostopoulos [16], for sandstone $\alpha=40$ and $c=10$ :

$E=a+c\left(N_{\mathrm{SPT}} \pm 6\right)=40+10(100 \pm 6) \approx 104 \mathrm{MPa}$.

According to Stround and Butler [? ], for $P l=6.3 \%$ we have $f_{2}=900$, so from the formula:

$$
E=f_{2} N_{\mathrm{SPT}} \gamma \iota \alpha N_{\mathrm{SPT}}=100,
$$

then

$$
E=90000 \mathrm{kN} / \mathrm{m}^{2}=90 \mathrm{MPa} .
$$

For depths less than $\mathbf{2 0}$ m. According to Schultze and Menzenbach [?] for sandstone with $N_{\mathrm{SPT}}=48$ we have:

$$
E=C+1+C_{2} N_{\mathrm{SPT}}=38+10.5 \cdot 48 \approx 50 \mathrm{MPa} .
$$

According to Tassios and Anagnostopoulos [16], for sandstone for $\alpha=40$ and $c=10$ we have:

$$
E=a+c\left(N_{\mathrm{SPT}} \pm 6\right)=40+10(48 \pm 6) \approx 50 \mathrm{MPa} .
$$

According to Stround and Butler [? ], for $\mathrm{Pl}=6.3 \%$ we have $f_{2}=900$ so from the formula:

$$
E=f_{2} N_{\mathrm{SPT}} \gamma \iota \alpha N_{\mathrm{SPT}}=48
$$

then

$$
E=43200 \mathrm{kN} / \mathrm{m}^{2}=43 \mathrm{MPa} .
$$

By the evaluation of the aforementioned relations and the results of the laboratory tests of the samples, parameters of geotechnical design were obtained, see Table 6.

By applying these geotechnical design parameters to the Phase 2 software program we obtained the results presented in Figures 9 and 10.

\section{Conclusions}

Based on the studied data, we have come to the conclusion that the factors which contributed to the appearance of these intense settlements in the section where the excavation of the tunnel was completed are the following:

- There was a significant difference between the real values of the geomechanical parameters and the values of the classification of the rock mass (GSI indicator) because of the degraded geomechanical properties of the ground. Actually, the entered 
values were the ideal ones. Thus, it was verified that the real values were much worse because of the bad quality of the ground.

- The existence of the ground water interaction in the area of the front.

By applying everything mentioned herein to the simulation model, we found that the values of the surface settlements approached $50-90 \mathrm{~mm}$ for both sections, which is closer to the real values.

These results appeared because a partial study and not a local survey of the project for the designation of the geotechnical parameters took place, as a local survey would be hard to accomplish financially.

For that reason, any potential failures were confronted on-the-spot with a change in the supporting measures. Interventions were made so that we could make proposals that would contribute to the estimation of the soil deformations that could be caused by any future earthquakes.

\section{ACKNOWLEDGements}

This project was supported by the National Technical University of Athens and the Athens Metro. We are grateful for their cooperation.

\section{REFERENCES}

[1] Athens Metro SA-Contractor K/O: Design of Extension Line 3, Section Egaleo-Chaidari, Transfer Station Chaidari. Report evaluation of results of geotechnical surveys, 2007.

[2] Athens Metro SA-Contractor K/O: Design of Extension Line 3, Section Egaleo-Chaidari, Transfer Station Chaidari. Report of geotechnical evaluation Main tunnel from the Alsos Well (C.H0+000) to the Iroon Politechniou Well (C.H0+500), 2007.

[3] Athens Metro SA-Contractor K/O: Design of Extension Line 3, Section Egaleo-Chaidari, Transfer Station Chaidari. Temporary support of the tunnel triple bisection from $\mathrm{CH}(0+000)$ to $\mathrm{CH}(0+349), 2007$.

[4] Athens Metro SA-Contractor K/O: Design of Extension Line 3, Section Egaleo-Chaidari, Transfer Station Chaidari. Temporary support of the tunnel double bisection from the $\mathrm{CH}(0+349)$ to $\mathrm{CH}(0+929), 2007$.

[5] Athens Metro SA-Contractor K/O: Design of Extension Line 3, Section Egaleo-Chaidari, Transfer Station Chaidari. Final report on geomechanical and structural observation, 2010.
[6] Davis, E. H.: Theories of plasticity and the failure of soil masses. In Soil mechanics: Selected topics (pp. 341-380). London, U.K.: Butterworth's, 1968.

[7] Duncan J.M, Buchignani A.L: An engineering manual for settlement studies. Geotechnical Engineering Report, University of California, Berkeley, 1976.

[8] Exadaktilos G., Stavropoulou M.: Construction and engineering of tunnels and underground works, Chania, 2006.

[9] Giatagana K.: Extension of metro of Athens, Line 3, Section Chaidari-Piraeus, National Technical University of Athens, 2014.

[10] Marinos G., Benisi M., Kokkoris K.: Investigation of the conditions that cause settlement during the mechanized opening of tunnels in urban environment. Experiences from the construction of the Athens Metro. 4th Panhellenic Conference of Geotechnical and Environmental Engineering, 537-544, Athens, 2001.

[11] Nakou F.A., Mavromati C.Z., Bousoulas N.Z.: Excavation of Double and Triple Track Tunnel with Conventional Tunnelling-Extension of Athens Metro Line 3, Section Egaleo-Haidari, 6th Panhellenic of Geotechnical and Geo-environmental Engineering Conference, Volos, 2010.

[12] Papavgeri G., Arvaniti A.: Deep excavations in urban area: The case of station of Metro "Agia Varvara," National Technical University of Athens, 2012.

[13] Sampatakakis N.: The technical characteristics of rocks - effect of geological characteristics of materials on technical works, Athens, 2007.

[14] Sotirchos A.: Geotechnical conditions during the tunnelling of Platanos and Trapezas of G.S.Y.T Kiatou-Aigiou. Application of analytical approaches for the determination of the interaction shoring and surrounding rock mass, Patra, 2011.

[15] Stroud M.A., Butler F.G.:The standard penetration test and the engineering properties of glacial materials, Conf. on the engineering behaviour of glacial materials, Univ. of Birmingham U.K, 1975.

[16] Tassios T., Anagnostopoulos A.: Penetration Testing in Greece, state of the Art Report, Proceedings of the 1st European Symposium on the Penetration Testing, Stockholm, Sweden, 1974.

[17] Tsiampaos G.: Newer aspects on the parameters of mechanical behaviour of rocks, Athens, 2009. 